\title{
A Proposal of Business Model Design Parameters for Future Internet Carriers
}

\author{
Antonio Ghezzi \\ Politecnico di Milano, \\ Department of Management, \\ Economics and Industrial Engineering \\ via Lambruschini 4B, 20156 Milan, Italy \\ Antonio1.ghezzi@polimi.it
}

\begin{abstract}
Future Internet evolution requires innovative strategic stances and the design of original business models from actors involved in the ecosystem. The study focuses on Internet Carriers, recently striving to make their business sustainable, and proposes to enclose in a single reference framework all the critical levers, either consolidated or innovative, such actors can employ in order to design their value proposition, value network integration, and financial configuration. The framework grounds its findings on multiple case studies, and, by presenting an insightful list of business model parameters for Carriers, sheds light on key emerging strategic and tactical trends in the Internet interconnections market.
\end{abstract}

Keywords: Future Internet, Carriers, Business Model Design, Strategy, Interconnections.

\section{Introduction}

The Internet's future development is not only heavily depending on its technological evolution, but also on business sustainability for the interconnection ecosystem the Web relies on, where various players characterized by fairly different economics are coexisting [3].

Current Internet technologies and business rules for network interconnection are proving to be no longer able to support the sustainable development of all actors along the value network, i.e. from the application to the network service providers. While Over-The-Top (OTT) providers develop high performance applications that create new revenues opportunities for them, Carriers have to cope with more and more constrainable traffic they cannot control and charge in order to recover corresponding extra network investment costs [18]. Indeed, peering agreements remain static and insensitive with respect to Quality of Service parameters, and operators rely mainly on the revenues coming from flat rate pricing in access networks.

To lighten this quite gloomy picture, Internet Service Providers (ISP) or Carriers are required to elaborate innovative strategies, in turn resulting in original tactical choices at a business model design level. The present study, through collecting the multifaceted perspectives of 10 Carriers (integrated by the complementary view of 5 
OTTs), aims at disclosing such strategic and tactical decisions (either already consolidated in the current market practices, or innovatively derived from original stances) and present them in a comprehensive framework for to support Carriers in the business model design process from a Future Internet perspective.

\section{$2 \quad$ Methodology}

The research leverages on two main methodological pillars: literature review and multiple case studies. The literature review focused on the significant and quite innovative stream of the broad Strategic Management theory. i.e. Business Model Design, posing the theoretical bases for the proposed Carriers model's building blocks.

With reference to the empirical research methodology, case studies are defined [15] as "empirical inquiries that investigates a contemporary phenomenon within its real-life context, especially when the boundaries between phenomenon and context are not clearly evident; and in which multiple sources of evidence are used". Qualitative research methodology is particularly suitable for reaching the research objectives, which aim at understanding the complex phenomenon of Business Model design within a given industry - that is, the Internet Interconnections Industry - characterised by a high level of dynamicity and competitive turbulence, and at thus building new theory, or extending existing theories, on such context [13].

To accomplish the previously identified research propositions, exploratory case studies based on semi-structured interviews are performed on a set of 15 companies operating in the broad Internet Interconnection market, and belonging to two major categories: Carriers (10 cases: British Telecom; Deutsche Telekom; France Telecom; Telecom Italia; Telefonica; Telenor; Fastweb; Tiscali; Colt; Libero Infostrada) and OTT/Content Providers (5 cases: Akamai; Google; Yahoo; Buongiorno; Dada).

The interviews focused on addressing which are the most critical choices to be made at a Business Model design level for Carriers. The semi-structured nature of the interview allows to start from some key issues identified through the literature, but also to let any innovative issue emerge from the open discussion.

As argued in [7], a multiple case studies approach reinforces the generalisation of results obtained, and allows to perform a cross analysis on Business Models characteristics and their combinations, due to the presence of extreme cases, polar types or niche situations within the theoretical sample. As the validity and reliability of case studies rest heavily on the correctness of the information provided by the interviewees and can be assured by using multiple sources or looking at data in multiple ways, several sources of evidences or research methods are to be employed: interviews (to be considered the primary data source), analysis of internal documents (both official and informal), study of secondary sources on the firm (i.e. research reports, websites, newsletters, white papers, databases, and conferences proceedings). This combination of sources allows obtaining perceptual triangulation, essential for assuring rigorous results in qualitative research.

\section{$3 \quad$ Literature Review}

The concept of business model generally refers to the "architecture of a business" or the way firms structure their activities in order to create and capture value [10] [12] [14]. 
As a literature stream, business model design has evolved from a piecemeal approach that looked for the single identification of typologies or taxonomies of models [1] [10] [11] [14] to one searching for the development of a clear and unambiguous ontology [9] - that is, the definition of the basic concepts of a theory - that could be employed as a generalized tool for supporting strategy analysis of firms. In parallel, business model has become an extensive and dynamic concept, as its focus has shifted from the single firm to the network of firms, and from the sole firm's positioning within the network to its entire interrelations and hierarchies [2].

It is widely accepted in literature that a business model shall be analyzed through a multi-category approach, as a combination of multiple design dimension, elements or building blocks. However, the proposed dimensions and interrelations are quite diverse, and the existing body of knowledge shows a lack of homogeneity [6].

Noteworthy attempts of providing a unified and consistent framework can be found in several works. Yu [16] mentions different critical business model components such as assets, markets, customers, competitors, products, services, costs, prices, revenues, profits, market shares, economic scales, marketing strategies, competitive advantages. According to Hedman and Kalling [5], the conceptual business model should include elements such as customers and competitors, the offering, activities and organization, resources and factor market interactions. Osterwalder, in his proposed business model design template [9], identifies four key dimensions for a business model: infrastructure; offering; customers; and finance. Morris and others [8] propose a six-component framework for characterizing a business model, regardless of venture type, which comprehends: value creation; value target; internal source of advantage; firm market positioning; value capture; entrepreneur's time, scope and size ambitions. Ballon [2] holds that the recurrent parameters a business model is built on can be brought back to the general concepts of value - value proposition and financial configuration - and control - interfirm or value network relationships -. For Johnson and others [6] a business model consists of four interlocking elements that, taken together, create and deliver value: customer value; profit formula; key resources; and key processes. Recently, Zott and Amit [17] suggest two sets of parameters that systems designers need to consider: design elements content, structure and governance - that describe the architecture of an activity system; and design themes - novelty, lock-in, complementarities and efficiency - that describe the sources of the activity system's value creation.

Notwithstanding the presence of several alternative frameworks for business model design, the literature review allows to claim most studies converge and focus on the concept of value: either it is the value a firm plans to offer to its customers (i.e. value proposition); or the value it creates, shares and competes for with other external actors in its market, depending on the level and nature of its value network integration; or, in the end, the value as a result of the proper selection of a cost structure and a revenue model [4].

\section{Business Model Design Parameters for Future Internet Carriers}

The research carried out through the multiple case studies allowed to shed light on the core business model design parameters for Carriers in the Internet Interconnections market. The findings are synthesized in the BM Framework below provided, which identifies 
three macro-dimensions. The macro-dimensions are in turn divided into 12 parameters. The framework is mainly directed to Carriers or Internet Service Providers (ISPs) as the referencing actor.

1. Value Proposition Parameters. It addresses the firm's strategic positioning by considering key business dimensions.

(a) Product/Service delivered (basic connectivity vs. ASQ vs. Content)

(b) Target customer (Content Provider/OTT vs. End User)

(c) Customer value (basic connectivity vs. Assured Service Quality vs. Content)

(d) Resources and Competencies (technology-oriented vs. content-oriented)

2. Value Network Parameters. It addresses the firm's level of integration within its referencing Value Network system.

(a) Vertical Integration (Infrastructure layer vs. Internet Service Layer)

(b) Customer Ownership (Direct vs. Indirect)

(c) Interconnection modality (prevalent: transit vs. peering)

(d) Content delivery model (Client-Server vs. Cloud vs. CDN)

3. Financial Configuration Parameters. It addresses the firm's configuration generating revenue and cost streams.

(a) Revenue Model (Single Transaction vs. Subscription)

(b) Revenue Sharing Model (Present vs. Absent)

(c) Traffic Charging scheme (Receiving Party Network Pays model vs. Congestion-charging model vs. Sending Party Network Pays model)

(d) Cost Model (concentrated vs. distributed)

For each and every parameter, the "value range" is identified, i.e. the extremes values or key alternatives the variables can assume, which also represent the major trade-off between opposite choices; the main strategic implications deriving from alternative parameters adoption are also discussed.

Table 1. Business Model Design Parameters for Future Internet Carriers

\begin{tabular}{|l|l|l|l|}
\hline & $\begin{array}{l}\text { Business Model } \\
\text { Parameter }\end{array}$ & $\begin{array}{l}\text { Value Range } \\
\text { (Trade-off) }\end{array}$ & $\begin{array}{l}\text { Strategic } \\
\text { Implications }\end{array}$ \\
\hline & & Basic connectivity & $\begin{array}{l}\text { Traditional business for ISPs. } \\
\text { Easier diffusion/substitution. } \\
\text { Higher potential margins from connectivity. }\end{array}$ \\
& & $\begin{array}{l}\text { Assured Service } \\
\text { Quality (ASQ) }\end{array}$ & $\begin{array}{l}\text { Service differentiation } \\
\text { Two-tiered internet. Net Neutrality broken. } \\
\text { Traditional business for CP/OTT. }\end{array}$ \\
& $\begin{array}{l}\text { Product/Service } \\
\text { Delivered }\end{array}$ & $\begin{array}{l}\text { Higher margins from content market making. } \\
\text { Higher complexity, ISP business diversification }\end{array}$ \\
\hline & & $\begin{array}{l}\text { Comparable relative bargaining power. } \\
\text { High data traffic to/from single customer } \\
\text { Peering agreements potentially required. }\end{array}$ \\
& Target Customer & Provider/OTT & $\begin{array}{l}\text { Higher relative bargaining power. } \\
\text { Low data traffic to/from single customer. } \\
\text { Investment in Access Network (last mile). }\end{array}$ \\
\hline
\end{tabular}


Table 1. (continued)

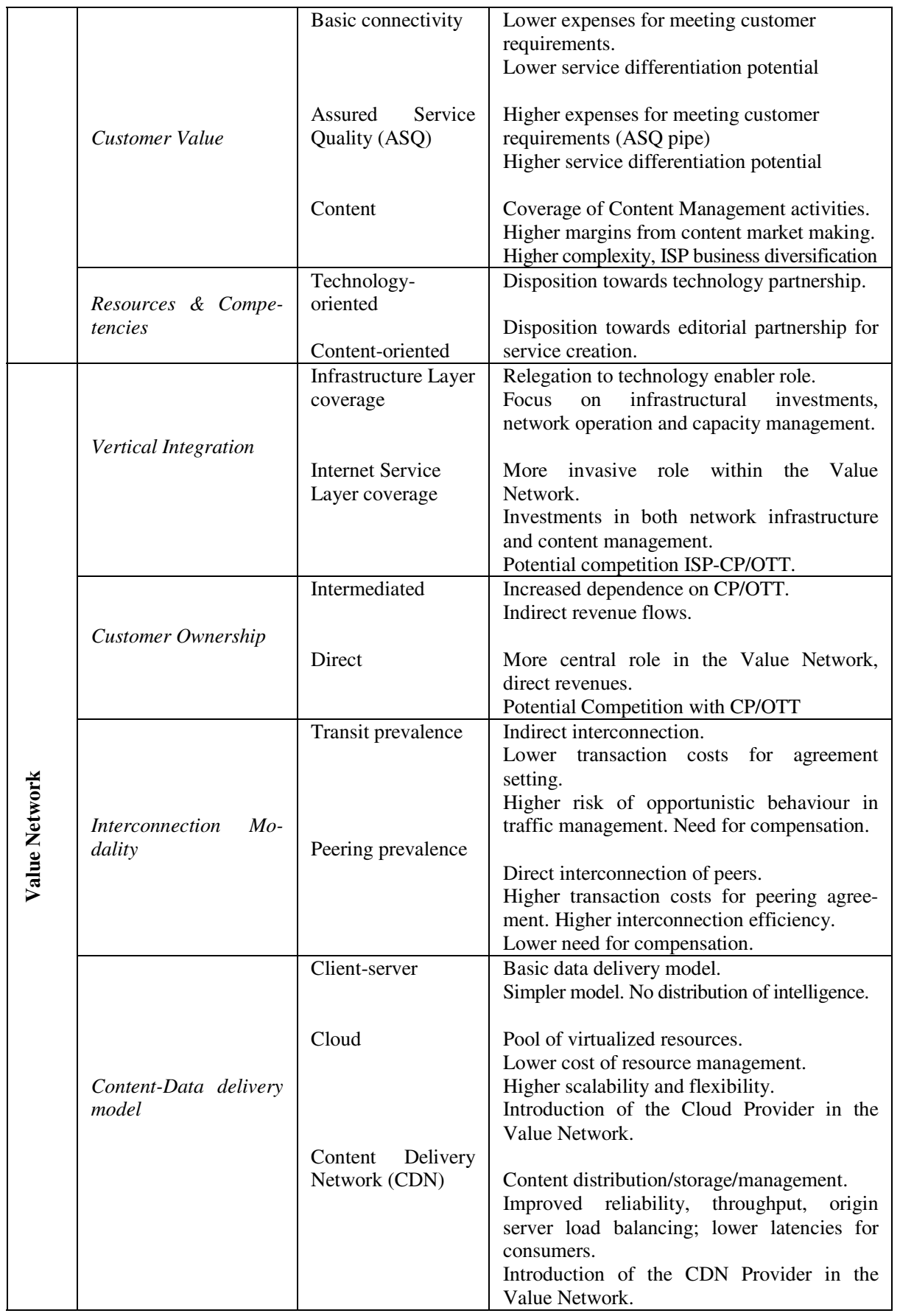


Table 1. (continued)

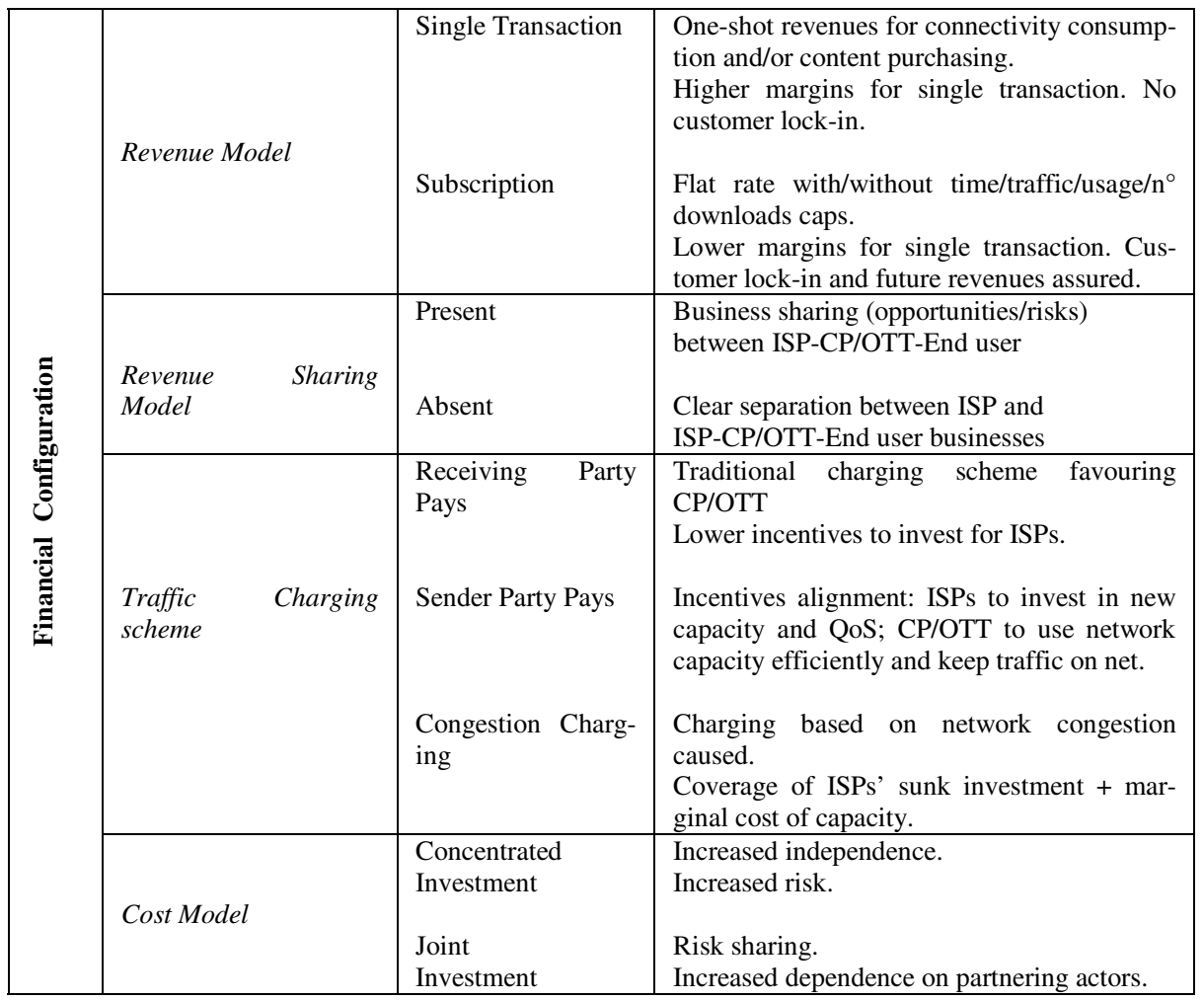

\section{Discussion and Conclusions}

The framework proposed for supporting the business model crafting for Future Internet Carriers discloses a number of emerging strategic and tactical trends ongoing within the Internet Interconnection market.

Carriers' value proposition is moving from basic connectivity provisioning to the elaboration of an ASQ offer towards end users or OTTs/CPs, in order to incorporate a larger share of the overall market value. To avoid being gradually left aside in a more and more peripheral value network position, Carriers should also strive to maintain direct customer ownership and a coverage of the Internet value added services layer, by becoming enablers and partners of the OTTs/CPs services offer which requires higher and higher quality of service, from several perspectives (e.g. bandwidth; low latency); peering interconnections, as well as Cloud/CDN solutions, should be deployed wisely by taking into fair consideration the strategic and tactical implications of such technological configurations. Carriers' current financial configuration should be redesigned by evaluating the option of introducing innovative revenue sharing models and traffic charging schemes (e.g. Sending party pays model, Congestion charging) towards OTTs/CPs, with the ultimate goal of enhancing the business' financial sustainability. 
These abovementioned considerations prove the reference model (solidly grounded in business model design theory) holds a straightforward value for Carriers' top managers, who can adopt it as a checklist of strategic and tactical decisions to be taken, and directly associate them to their implications.

Future studies should aim at testing the validity of the model within different firm samples, and, in turn, assess the relationship between specific choices in the business model parameters combination and firm performance.

Acknowledgments. The research leading to these results has received funding from the European's Community Seventh Framework Programme (FP7/2007-2013) under grant agreement $\mathrm{n}^{\circ} 248567$ for the 'ETICS' Project. Further information is available at www.ict-etics.eu. The authors would like to thank all members of the ETICS project for many valuable discussions and feedback.

\section{References}

1. Amit, R., Zott, C.: Value creation in e-business. Strategic Management Journal 22, 493$520(2001)$

2. Ballon, P.: Business modelling revisited: the configuration of control and value. Info. 9(5), 6-19 (2007)

3. Clark, D., Wroclawski, J., Sollins, K., Braden, R.: Tussle in Cyberspace: Defining Tomorrow's Internet. IEEE Transaction on Networking 13(3) (June 2005)

4. Ghezzi, A., Balocco, R., Rangone, A.: How to get Strategic Planning and Business Model Design wrong: the case of a Mobile Technology Provider. Strategic Change 19, 213-238 (2010), doi:10.1002/jsc.871

5. Hedman, J., Kalling, T.: The business model concept: theoretical underpinnings and empirical illustrations. European Journal of Information Systems 12(1), 49-59 (2003)

6. Johnson, M.W., Christensen, C.M., Kagermann, H.: Reinventing your business model. Harvard Business Review, 50-59 (December 2008)

7. Meredith, J.: Building operation management theory through case and field research. Journal of Operations Management 16, 441-454 (1998)

8. Morris, M., Schinderhutteb, M., Allen, J.: The entrepreneurs business model: toward a unified perspective. Journal of Business Research 58(6), 726-735 (2005)

9. Osterwalder, A.: The Business Model Ontology. A proposition in a design science approach. PhD thesis, École des Hautes Études Commerciales de l'Université de Lausanne (2004)

10. Rappa, M.: Business Models on the Web: Managing the digital enterprise. North Carolina State University (2001)

11. Tapascott, D., Ticoll, D., Lowy, A.: Digital Capital: Harnessing the Power of Business Webs. Harvard Business School Press, Boston (2000)

12. Timmers, P.: Business models for electronic commerce. Electronic Markets 8(2), 3-8 (1998)

13. Walsham, G.: Interpretive case-studies in IS research - nature and methods. European Journal of Information Systems 4(2), 74-81 (1995)

14. Weill, P., Vitale, M.: Place to Space: Migrating to E-Business Models. Harvard Business Press, Boston (2001) 
15. Yin, R.: Case Study Research: Design and Methods. Sage Publishing, Thousand Oaks (2003)

16. Yu, C.-C.: An Integrated Framework of Business Models for Guiding Electronic Commerce Applications and Case Studies. In: Bauknecht, K., Madria, S.K., Pernul, G. (eds.) EC-Web 2001. LNCS, vol. 2115, pp. 111-120. Springer, Heidelberg (2001)

17. Zott, C., Amit, R.: Business model design: an activity system perspective. Long Range Planning 43(2-3), 216-226 (2010)

18. Zwickl, P., Reichl, P., Ghezzi, A.: On the Quantification of Value Networks: A Dependency Model for Interconnection Scenarios. In: Cohen, J., Maillé, P., Stiller, B. (eds.) ICQT 2011. LNCS, vol. 6995, pp. 63-74. Springer, Heidelberg (2011) 